\title{
Subterranean biodiversity in New South Wales: from rags to riches
}

\author{
Mia E. Thurgate ${ }^{1 *}$ Jane S. Gough², Andy Spate ${ }^{2}$ and Stefan Eberhard ${ }^{3}$ \\ Jenolan Caves Reserve Trust, Locked Bag, Jenolan Caves, New South Wales 2790, Australia \\ e-mail: karst@jenolancaves.org.au \\ ${ }^{2}$ New South Wales National Parks and Wildlife Service, PO Box 2115, Queanbeyan, New South Wales 2620, Australia \\ ${ }^{3}$ CaveWorks, PO Witchcliffe, Western Australia 6286, Australia \\ *For correspondence
}

\begin{abstract}
The karst areas of New South Wales, Australia, support a diverse invertebrate subterranean fauna with up to 422 taxa recognised to date, of which 83 are obligate subierranean taxa. The terrestrial fauna is dominated by arachnids and insects and includes 45 terrestrial obligate taxa. A rich stygofauna has also been identified that contains 38 stygobites, dominated by crustaceans. Five karst areas are particularly important as focal points for biodiversity. Jenolan, Wombeyan, Wee Jasper and Stockyard Creek contribute significantly to the total subterranean fauna, while Wombeyan and Wellington are exceptional for their stygobitic communities. High levels of richness and endemism, as well as relictual distributions and ancient lineages highlight the significance of the fauna.
\end{abstract}

\section{INTRODUCTION}

Recent research has demonstrated that some Australian karst areas support rich subterranean invertebrate faunas, particularly in the States of Tasmania, Queensland and Western Australia (Howarth and Stone, 1990; Doran et al., 1997; Humphreys, 2000a). This paper focuses on the issue of subterranean biodiversity in another region of Australia, namely the karsts of New South Wales and the Australian Capital Territory (hereafter included with New South Wales). Hamilton-Smith (1967) compiled the first systematic review of the total Australian cavernicolous fauna and found that the karsts of New South Wales had a comparatively richer fauna than elsewhere on the continent. Gray's (1973) subsequent review of the Australian cave spider fauna added further to the tally provided by Hamilton-Smith. In all, these two papers listed 84 cavernicolous species from New South Wales.

In the two decades following the publication of these reviews, new records and descriptions of subterranean invertebrates from New South Wales accumulated slowly and survey efforts lagged behind other areas in Australia. However, some significant increases in knowledge resulted from baseline surveys of particular karsts. For example, the results of intensive surveys at Jenolan Caves almost doubled the known subterranean diversity of the state (Gibian et. al., 1988; Greenslade, 1989).

Sufficient information had been published by the early 1990s to indicate that a rich fauna would be uncovered by further surveys. However, this information was widely scattered, difficult to access, and had not been collated. Furthermore, a long-held preoccupation with obligate forms (of which relatively few had been discovered) did not allow an appreciation of the diversity of the entire spectrum of cavernicolous invertebrates. Consequently, a perception arose that the fauna of New South Wales was depauperate and insignificant in comparison to that being discovered elsewhere in Australia (Eberhard and Spate, 1995).

In 1995 a reconnaissance survey was completed covering many karst areas in New South Wales (Eberhard and Spate, 1995). The results of this and more recent surveys have markedly increased the known diversity of the subterranean fauna. We use the metaphor 'from rags to riches' to highlight this finding and to dispel former erroneous perceptions of a depauperate fauna. The information provided in this paper is largely drawn from an analysis of these surveys, and many of the results are reported for the first time. Specifically, we present information regarding the composition, distribution and diversity of the fauna and highlight its significance.

\section{CHARACTERISTICS OF THE SUBTERRANEAN FAUNA}

The present knowledge of the subterranean faunas of New South Wales is far from complete owing to the limited survey and taxonomic effort. 
Currently many genera and most species remain undetermined. Most caves have been sampled only once so data on annual, seasonal and longer-term variations of population and community dynamics is lacking. There are many distributional gaps in the data as only $10 \%$ of caves, and $70 \%$ of cavernous karst areas have been surveyed (Eberhard and Spate, 1995). Owing to the taxonomic limitations we have adopted a conservative approach and treat multiple specimens, not clearly assigned to a

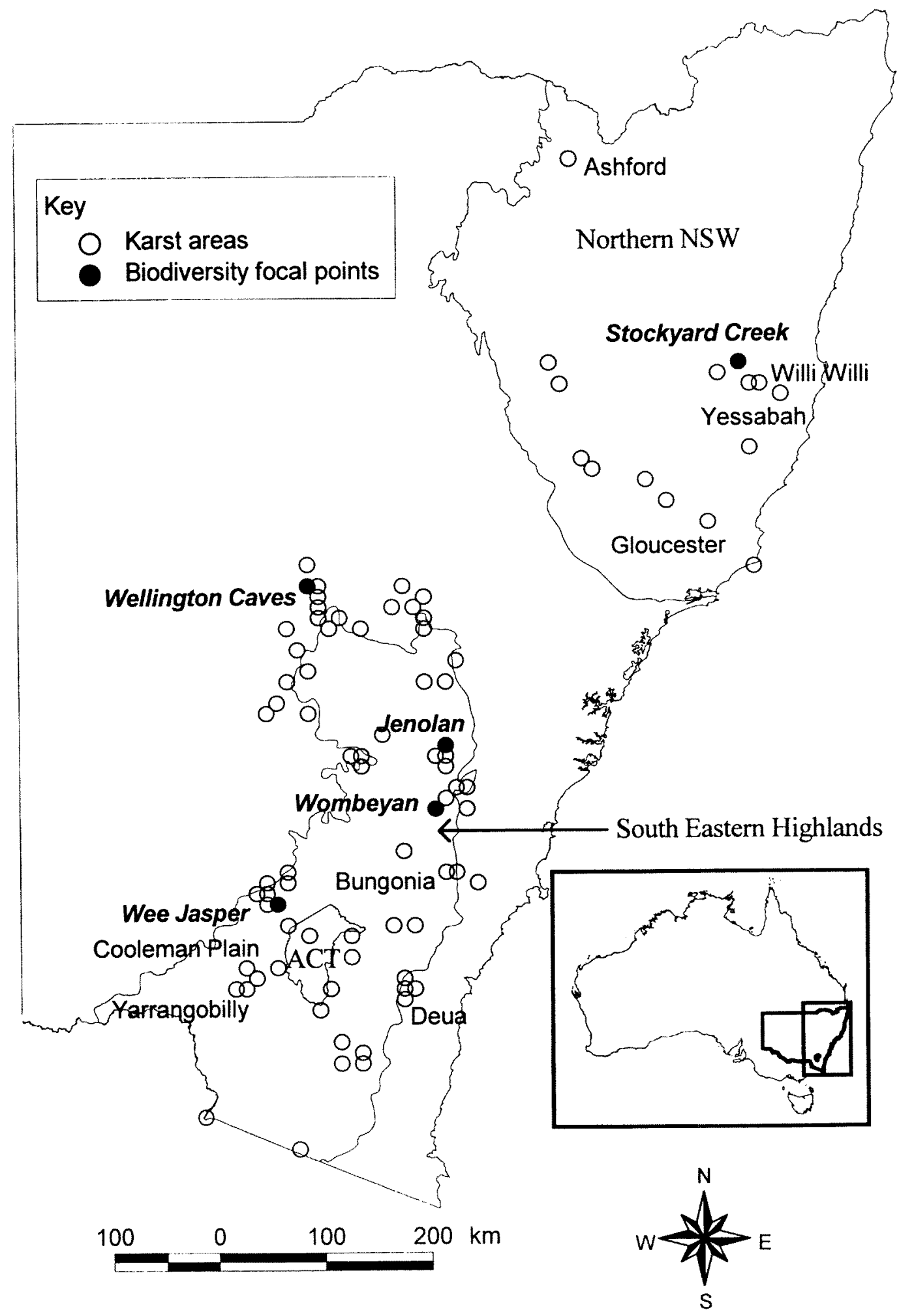

Figure 1 Distribution of cavernous karst areas in New South Wales including localities mentioned in the text. Note that the karst areas fall into two broad groups (northern and southern), with most being concentrated in and around the South Eastern Highlands. Areas supporting a high subterranean invertebrate diversity are highlighted. 
particular species, as a single taxon. Hence, it is likely that the diversity of the fauna is far greater than is presented here.

\section{Composition}

Insects and arachnids predominate the karsts of New South Wales accounting for three-quarters of the total fauna. The most diverse insect orders are Coleoptera, Collembola, Diptera and Lepidoptera. The arachnid fauna is dominated by Araneae, but includes Acarina, Opiliones and Pseudoscorpiones. Crustacea, Myriapoda and Gastropoda account for a further $21 \%$ of the fauna.

\section{Terrestrial fauna}

Insects, arachnids, gastropods and myriapods dominate the terrestrial fauna. They form distinct communities associated with particular habitats such as twilight and entrance zones, plant detritus, sediment banks, rock surfaces, tree roots and bat guano (Smith, 1982; Eberhard and Spate, 1995; Eberhard, 1998). Little is known about the ecology of these communities. Some specialised taxa are restricted to a particular type of habitat (eg. tineid moths in bat guano and fulgoroid planthoppers on tree roots), while others are generalists and occur across a range of habitats.

The faunas associated with bat guano deposits were amongst the earliest to be collected and studied, and consequently are better understood than most. The guano-based communities in New South Wales typically include spiders, pseudoscorpions, mites, tineid moths, springtails, pscopterans and beetles (Eberhard and Spate, 1995; Hamilton-Smith and Eberhard, 2000). One of the few Australian studies on the structure and dynamics of an invertebrate cave community (Harris, 1973) was based on guano communities from Carrai Bat Cave at Stockyard Creek. This location (and all others mentioned in the text) is shown in Figure 1.

\section{Aquatic fauna}

Crustaceans, especially amphipods and syncarids, dominate the subterranean aquatic fauna. Other (minor) taxa include oligochaetes, mites, hydrobiid gastropods, paludicolan flatworms, and various insect orders. Distinctive communities are associated with flowing waters, pools, edge environments, and different substrate types such as coarse sediments or tree root mats (Eberhard, 1993 1998; Thurgate and Gough, unpublished). The composition of the subterranean aquatic fauna of New South Wales is discussed in greater detail in Thurgate et al. (2001).

\section{Obligate faunas}

The New South Wales faunas display varying degrees of dependency on subterranean environments. We have adopted the approach of Humphreys (2000b) to define dependency. Hence for terrestrial faunas, troglobites are forms only found in subterranean environments while troglophiles occur in both hypogean and epigean environments. Both troglobites and troglophiles spend their entire lifecycle underground. Trogloxenes enter caves actively or passively, and normally feed on the surface. Subterranean aquatic forms are classified as stygobites, stygophiles and stygoxenes using similar criteria.

Some authors have used the degree of morphological adaptation as an additional criterion to identify cave-dependent faunas (see Camacho, 1992). Many terrestrial obligates found in earlier New South Wales surveys (particularly the spiders and insects) display little or no adaptation. This prompted Hamilton-Smith $(1967,1971)$ to introduce the term second-level troglophile to distinguish "those forms living out their total life-cycle within caves, known only from caves, but not exhibiting any modification to the cave environment" (HamiltonSmith, 1971: 64). Use of this term detracts from the fact that these forms are an important component of the obligate fauna, so we do not distinguish between troglobites and second-level troglophiles in this paper. However, as the term persists in the Australian literature we indicate taxa previously identified as second-level troglophiles in the Appendix.

In contrast to the terrestrial obligate fauna, most stygobionts are highly troglomorphic (lacking eyes and pigment). Many also have Pangaean and Gondwanan affinities (see Thurgate et al., 2001) or are distributional and/or phylogenetically relict taxa (Hamilton-Smith and Eberhard, 2000; Serov, personal communication, 2000; Wilson and Johnson, 1999). This suggests that some karst regions have acted as long-term refuges (sensu Humphreys, 2000b) for stygofauna (Eberhard and Spate, 1995). The distribution of karst areas that contain obligate faunas is shown in Figure 2.

Based on current estimates, up to $20 \%$ of New South Wales subterranean invertebrates are obligate species, while similar proportions are troglophiles and stygophiles. For the terrestrial faunas, most obligate species are found in the Araneae (11 species), Pseudoscorpiones (8 species) and Coleoptera ( 6 species). Amongst the aquatic fauna stygobites occur mostly in the Amphipoda (16 species) and Anaspidaceae (12 species).

\section{Distribution patterns}

The karsts of New South Wales occur as a broad band of scattered outcrops in the east of the State. Most are located in and around the South Eastern Highlands, while a smaller cluster occurs in northern New South Wales (Figure 1). The South 


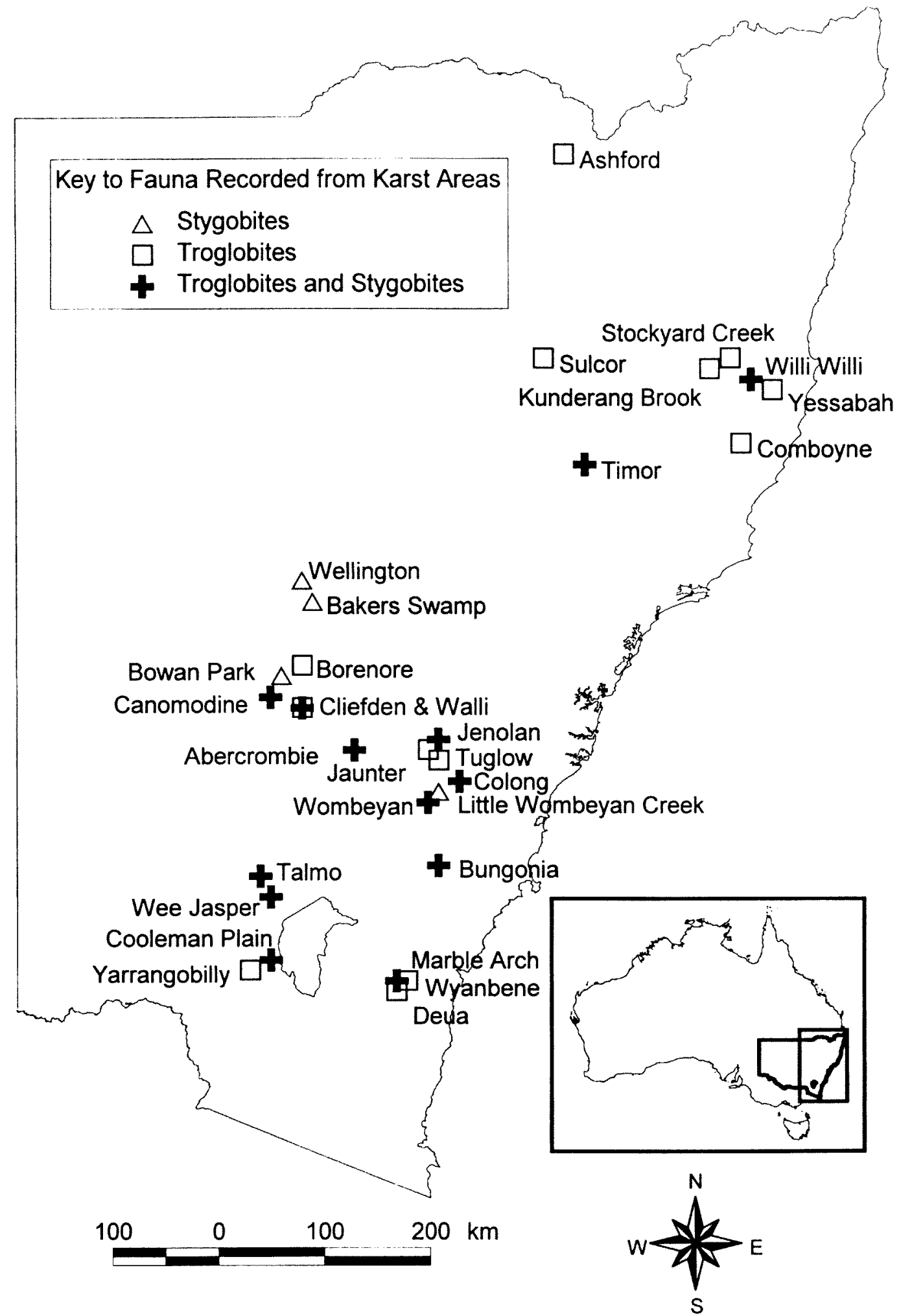

Figure 2 Distributions of karsts in New South Wales that contain obligate fauna. Sites marked 'troglobite' may include a number of taxa that are considered to be second-level troglophiles. A full list of obligate taxa and their distribution is provided in the Appendix.

Eastern Highlands are characterised by cool, moist climates, and these karst systems are impounded (surrounded by non-carbonate rocks) and of low relief. In contrast, the karsts of northern New South Wales are characterised by a warm, seasonally moist climate, and most occur as small, isolated outcrops often rising above the surrounding landscape.

The broad-scale distribution patterns of the fauna reflect the characteristics of the karsts themselves. The disjunct nature of the karsts is reflected by similarly highly disjunct distribution patterns 
amongst the subterranean fauna. Most of the fauna is concentrated in the karsts of South Eastern Highlands, which also contain a higher proportion of aquatic communities and obligate taxa.

The northern and southern karsts each contain distinctive faunal elements, and it has been suggested that the gap between these areas may have acted as a barrier to dispersal (Hunt, 1992). For example, the genus Speotarus occurs only in the north of the State whilst Notospeophonus is found only in the south. Interestingly the Mycetophilidae, represented by the single species Arachnocampa richardsae Harrison, 1966, are relatively common in abandoned mines, moist canyons and gullies in the South Eastern Highlands, and generally in rainforest environments. Only in the north of the State are they found in caves and then only at Gloucester and Stockyard Creek. Both areas contain caves with running streams and, unlike most of the State's karsts, are beneath rainforest, so it is unlikely that the gap in karst distribution has been significant in this instance.

Most arachnids are scattered in disjunct populations across the State, but there is evidence to suggest a dispersal barrier has influenced some of this fauna. Colcarteria and Heteropoda and Pholcidae are found only in northern karsts. In contrast, Kaiya, Badumna and Australomimetus are predominantly southern in distribution. Similarly, within the harvestmen, Megalopsalidae is broadly scattered, but Triaenonychidae is mostly confined to karsts in the South Eastern Highlands.

The genus Holonuncia (Triaenonychidae) forms a complex of 12 species in New South Wales (Hunt, 1992), of which six species occur only in surface environments. Three species are found in both epigean and hypogean environments, however cave populations display minor adaptations and may be genetically isolated from surface congeners. Holonuncia sussa, $H$. dewae and $H$. weejasperensis are obligate cavernicoles (Hunt, 1992). A similar distribution pattern may be evident amongst other arachnids (e.g. Laetesia spp., Archaearanae and Pholcidae). These epigean/hypogean species-complexes may prove useful in testing biogeographic and evolutionary hypotheses about the Australian cave fauna (Eberhard, 1998).

\section{Endemism}

Cave communities in New South Wales possess a very high degree of local endemicity as is typical of many karst areas worldwide (Culver, 1982). A preliminary analysis by Thurgate et al. (in press) found that up to half of the total subterranean fauna of the State is restricted to a single karst area. There are also a number of centres of endemism, notably Wombeyan and Jenolan in the south and the
Macleay Valley, between Yessabah and Stockyard Creek, in the north (Figure 1).

Amongst the terrestrial fauna, some species are endemic to a karst area but occur in several caves (e.g. Australotettix carraiensis, Trinemura anenome and Progradungula carraiensis). Amongst the beetle fauna 11 of 25 families contain taxa that are local endemics. Some subterranean invertebrates have an even more restricted distribution, being limited to single caves (e.g. Speotarus lucifugus princeps, Teraphis cavicola and Laetesia weburdi). Culver (1986) identifies single cave endemism as a feature common to dissected karsts such as those found in New South Wales.

Endemism is also extremely high in the aquatic faunas, particularly amongst the amphipods and syncarids. Of the 63 stygobionts, 27 are restricted to single cave systems. The crustacean fauna found at Wombeyan is almost exclusively endemic to that area and most species are restricted to single caves (Thurgate et al., 2001).

\section{DIVERSITY OF NEW SOUTH WALES SUBTERRANEAN FAUNA}

The subterranean invertebrate fauna of New South Wales includes 422 species from 269 genera and 166 families. Most of this richness is concentrated in the terrestrial fauna (359 taxa), particularly amongst the insects and arachnids. The dominant insect orders are Coleoptera, Collembola and Diptera, while Araneae is the most diverse arachnid order (Table 1). The aquatic communities

Table 1 Richness within taxonomic groups recorded from New South Wales caves. Values represent the minimum number of taxa present based on available taxonomic information. Based on the New South Wales Cave Invertebrate Database (Eberhard and Spate, 1995) and unpublished records.

\begin{tabular}{lccc}
\hline Taxa & $\begin{array}{c}\text { Number of } \\
\text { families }\end{array}$ & $\begin{array}{c}\text { Number of } \\
\text { genera }\end{array}$ & $\begin{array}{c}\text { Number of } \\
\text { species }\end{array}$ \\
\hline Arachnida & & & \\
$\quad$ Acarina & 12 & 12 & 17 \\
$\quad$ Araneae & 34 & 66 & 111 \\
$\quad$ Pseudoscorpiones & 7 & 9 & 15 \\
$\quad$ Opiliones & 2 & 3 & 14 \\
Insecta & & & \\
$\quad$ Coleoptera & 25 & 42 & 61 \\
Collembola & 9 & 34 & 39 \\
$\quad$ Diptera & 14 & 15 & 20 \\
$\quad$ Other insect orders & 26 & 28 & 36 \\
Gastropoda & 9 & 14 & 23 \\
Crustacea & 14 & 28 & 45 \\
Myriapoda & 3 & 5 & 19 \\
Minor groups & 11 & 13 & 22 \\
\hline Totals & $\mathbf{1 6 6}$ & $\mathbf{2 6 9}$ & 422 \\
\hline
\end{tabular}


are less diverse (63 taxa), and Amphipoda (20 taxa) and Anaspidacea (12 taxa) are the richest orders.

At least 83 obligate taxa have been recorded from 30 karsts in New South Wales (see Appendix and Figure 3). This includes up to 45 terrestrial obligates and 38 stygobites. Spiders (11 taxa), pseudoscorpions ( 8 taxa) and beetles ( 6 taxa) are the richest groups in this instance. Once again, the Amphipoda and Anaspidacea (16 and 12 taxa, respectively) dominate the aquatic fauna as these two groups include most of the stygobites.

The abundance of individuals is generally low in both aquatic and terrestrial environments. Exceptions occur where there is a stable and abundant food supply, such as occurs in guano deposits and in aquatic plant root mats. For example, Harris (1973) recorded very high numbers (up to $34 \times 10^{6} / \mathrm{m}^{2}$ ) of the guano mite, Uroobovella coprophila in association with bacteria, protozoans, nematodes, spiders and insects at Stockyard Creek.

In most karst areas the stygobitic fauna is cryptic and in low abundances, but at Wellington, syncarids, amphipods and isopods are found in high densities and can easily be observed (Spate $e t$ al., 1999). Similarly, caves at Wombeyan support rich and abundant crustacean communities where root mats are present (S. Reilly, personal communication, 2000).

Comparisons with Tasmanian karsts provide a temperate-zone context for examining the richness of the. New South Wales' fauna, particularly as Tasmania is already recognised for its high subterranean biodiversity (Clarke, 1997; Doran et al., 1997). Within this context, it is interesting to find that the diversity of the fauna in New South Wales is comparable with that of Tasmania, particularly at higher taxonomic levels and for stygobitic fauna (Table 2).

Such comparisons need to be treated with caution. The setting, nature and extent of each state's karst areas and their environmental history are very different, as is the associated fauna. However, it is now apparent that New South Wales contributes a significant component of Australia's total subterranean biodiversity, and that the levels of

Table 2 Taxonomic and ecological richness of the subterranean invertebrate fauna of New South Wales compared to Tasmania.

\begin{tabular}{lrr}
\hline Variable & NSW $^{\mathbf{1}}$ & Tas $^{2}$ \\
\hline Number of families & 166 & 179 \\
Number of genera & 269 & 271 \\
Number of species (taxa) & 422 & 643 \\
Number of terrestrial obligates & 45 & 108 \\
Number of stygobites & 38 & 38 \\
\hline
\end{tabular}

${ }^{1}$ Eberhard and Spate (1995) and unpublished records to April 2000.

${ }^{2}$ Clarke (1997) and personal communication. taxonomic and ecological richness are much higher than has been appreciated previously.

\section{FOCAL POINTS OF BIODIVERSITY}

In a worldwide review, Culver and Sket (2000: 11) have used "an arbitrary cutoff of 20 or more obligate subterranean species for a site" to be identified as a biodiversity 'hotspot'. No single site in New South Wales is known to meet this criterion. However, Wombeyan must be considered a contender for this title with 19 confirmed obligate taxa, and a further seven that may fall into this category (see Appendix).

The use of a single numerical measure based on obligate forms is problematic as this reveals little about overall diversity and community dynamics. There are also problems of scale and of cave definition that confound the use of such arbitrary measures, problems readily apparent in Culver and Sket's review. Given our present knowledge, and without putting any numeric thresholds in place, several areas in New South Wales appear to stand out as focal points for subterranean biodiversity.

In the broader geographical context, and when the total subterranean fauna is considered, karst areas in the South Eastern Highlands are particularly diverse. Rich communities of both terrestrial (notably Holonuncia, Collembola, Carabidae and Chilopoda) and aquatic fauna (Amphipoda and Syncarida) are present. The northern karsts are also rich in terrestrial fauna including Gastropoda (Charopidae), Araneae (Pholcidae and Heteropodidae) and Hemiptera. The available evidence suggests that aquatic communities of the northern karsts are less species rich than those found in the South Eastern Highlands.

The overall richness (including obligate forms) and numbers of local endemics of some individual karst areas is quite high. The richest sites are Jenolan (126 taxa, 11 obligate and 30 endemic), Wombeyan (83 taxa, 19 obligate and 25 endemic), Wee Jasper (62 taxa, 11 obligate and 13 endemic) and Stockyard Creek (55 taxa, 6 obligate and 9 endemic). Collectively these sites support more than half of the State's subterranean fauna. Most other karsts contain less than 30 taxa and have few endemics or obligate forms.

The higher richness at Jenolan, Wombeyan, Wee Jasper and Stockyard Creek may reflect the greater survey efforts in these areas. However, the large size, greater relative relief, and highly cavernous structure at the first three locations may also influence richness by providing a wide range of habitats for colonisation. It has also been suggested that these karsts have been maintained as moist refuges over geologically significant time periods, 
thus facilitating the survival of relictual populations (Eberhard and Spate, 1995).

Most other New South Wales karst areas have a lower environmental buffering capacity owing to their smaller size, lower relief, fewer and smaller caves, or fewer habitats. Pleistocene arid periods may have completely desiccated smaller karsts thus eliminating the pre-existing subterranean invertebrates (Eberhard and Spate, 1995). This may have been particularly true for terrestrial faunas that have been more exposed to the effects of climate change than their aquatic counterparts.

Caves at Wombeyan contain diverse subterranean communities, and overall this location can be considered a focus of stygobitic diversity. At least 25 groundwater taxa have been collected from Wombeyan of which up to 15 taxa are stygobites. Of particular interest is the high diversity of amphipods, of which there are at least ten species (Eberhard and Spate, 1995) representing half of the known stygobitic amphipod diversity recorded for the State.

A number of karst areas are notable for species richness within a single order. Eberhard (1993) identified ten myriapods from one cave during a single survey at Deua, and also found nine different beetles at Willi Willi. Intensive survey and taxonomic efforts at Jenolan have also revealed a particularly rich collembolan fauna of 34 taxa from 14 caves. This includes taxa from Neanuridae and Neelidae, which have not been recorded in other New South Wales caves (Greenslade, in press).

\section{CONCLUSIONS}

This paper clearly demonstrates that the subterranean biodiversity of New South Wales has progressed from 'rags to riches' with the recognition of the rich and diverse fauna. Clearly, the fauna of New South Wales makes a significant contribution to the subterranean biodiversity of Australia. Many new families, genera and species have been discovered in the last five years alone. Overall, levels of endemism amongst the subterranean fauna are very high and many taxa show relictual and disjunct distribution patterns. Some of the fauna has Pangaean and Gondwanan affinities and will be important in testing phylogenetic and evolutionary theories. The high diversity of stygofauna, previously unsuspected in New South Wales, is also an important discovery (Eberhard and Spate, 1995).

The information presented here is a preliminary account of the significance of the State's fauna, and there is scope for much important research in the future. At the present time, we have species lists for a few selected caves in many scattered karst areas, with many have yet to be investigated. Little is known of the phylogeny or ecology of the fauna that has been collected, and there are many taxonomic groups yet to be described. This lag in taxonomic research is of particular concern and it is vitally important that funding be directed to this area if a full appreciation of the subterranean fauna is to be gained.

The future conservation and management of karst ecosystems in New South Wales must rest on a foundation of better public understanding, aided by further research and monitoring, in combination with legislative recognition of rare and threatened communities and species. To date, efforts in these areas have mainly focussed on obligate faunas. While we acknowledge that these are an important component, the identification of these faunas is problematic, particularly if morphological criteria are used. We advocate the adoption of a whole ecosystem approach for recognising and protecting the diversity of the State's subterranean invertebrates.

\section{ACKNOWLEDGEMENTS}

We wish to thank Bill Humphreys for organising the symposium at which this paper was presented. Buz Wilson, Peter Serov, Arthur Clarke, John Bradbury, Winston Ponder, Mike Gray and Barry Moore provided invaluable information that has been incorporated into this paper. We thank Alexander Herr for comments on early drafts of the manuscript, and our reviewers whose comments greatly enhanced the final paper. We also acknowledge the assistance of numerous cavers, divers, land managers and taxonomists without whom the New South Wales cave invertebrate database would not exist.

\section{REFERENCES}

Camacho, A.I. (1992). A classification of the aquatic and terrestrial subterranean environment and their associated fauna. In A.I. Camacho (ed.), The Natural History of Biospeleology: 57-103. Monografias Museo Nacional de Ciencias Naturales, Madrid.

Clarke, A. (1997). Management Prescriptions for Tasmania's Cave Fauna. Report to the Tasmanian RFA Environment and Heritage Technical Committee, Hobart.

Culver, D.C. (1982). Cave Life: Evolution and Ecology. Harvard University Press, Massachusetts.

Culver, D.C. (1986). Cave faunas. In M.E. Soulé (ed), Conservation Biology: The Science of Scarcity and Diversity: 427-423. Sinauer Associates, Massachusetts.

Culver, D.C. and Sket, B. (2000). Hotspots of subterranean biodiversity in caves and wells. Journal of Cave and Karst Studies 62: 11-17.

Doran, N.E., Eberhard, S.M., Richardson, A.M.M. and Swain, R. (1997). Invertebrate biodiversity and conservation in Tasmanian caves. Memoirs of the Museum of Victoria 56: 649-653. 
Eberhard, S. (1993). Survey of Fauna and Human Impacts in the Jenolan Caves Reserve. Report to Jenolan Caves Reserve Trust, Jenolan Caves.

Eberhard, S. (1997). Cave fauna of New South Wales: nomination of key threatening processes, endangered ecological communities, endangered populations and threatened species for inclusion on the Threatened Species Conservation Act 1995. Report to Scientific Committee, New South Wales National Parks and Wildlife Service, Queanbeyan.

Eberhard, S. (1998). Cave invertebrates. In J. Bauer and P. Bauer (eds), Under Bungonia: 74-83. J.B. Books, Oak Flats.

Eberhard, S. and Spate, A. (1995). Cave Invertebrate Survey: Towards an Atlas of NSW Cave Fauna. Report to Department of Urban Affairs and Planning and the Australian Heritage Commission, Canberra.

Gibian, M., Smith, G. and Wheeler, L. (1988). Interim Report on the Survey of the Invertebrate Fauna of Jenolan Caves. Report to Jenolan Caves Reserve Trust, Jenolan Caves.

Gray, M.R. (1973). Survey of the spider fauna of Australian caves. Helictite 11: 47-75.

Greenslade, P. (1989). Collembola from Jenolan Caves. Report to New South Wales National Parks Service, Canberra.

Greenslade, P. (in press). Diversity and latitudinal gradients in composition of Australian cave collembolan faunas including notes on some effects of disturbance. Pedobiologia.

Hamilton-Smith, E. (1967). The arthropoda of Australian caves. Journal of the Australian Entomological Society 6: 103-118.

Hamilton-Smith, E. (1971). The classification of cavernicoles. National Speleological Society Bulletin 33: 63-66.

Hamilton-Smith, E. and Eberhard, S. (2000). Conservation of cave communities in Australia. In $\mathrm{H}$. Wilkens, D.C. Culver and W.F. Humphreys (eds), Ecosystems of the World, Volume 30: Subterranean Ecosystems: 647-664. Elsevier, Amsterdam.

Harris, J.A. (1973). Structure and dynamics of a cave population of the guano mite Uroobovella coprophila (Womersley). Australian Journal of Zoology 21: 239-275.
Howarth, F.G. and Stone, F.D. (1990). Elevated carbon dioxide levels in Bayliss Cave, Australia: implications for the evolution of obligate cave species. Pacific Science 44: 207-218.

Humphreys, W.F. (2000a). The hypogean fauna of the Cape Range peninsula and Barrow Island, northwestern Australia. In H. Wilkens, D.C. Culver and W.F. Humphreys (eds), Ecosystems of the World, Volume 30: Subterranean Ecosystems: 581-601. Elsevier, Amsterdam.

Humphreys, W.F. (2000b). Background and glossary. In H. Wilkens, D.C. Culver and W.F. Humphreys (eds), Ecosystems of the World, Volume 30. Subterranean Ecosystems: 3-14. Elsevier, Amsterdam.

Hunt, G.S. (1992). Revision of the genus Holonuncia Forster (Arachnida: Opiliones: Triaenonychidae) with description of cavernicolous and epigean species from eastern Australia. Records of the Australian Museum 44: 135-163.

Smith, G. (1982). Broad similarities in the invertebrate fauna in NSW caves. Highland Caving Group Journal 3: 26-30.

Spate, A., Gough, J. and Thurgate, M. (1999). Karstic groundwater ecosystems in the Murray Darling and Otway Groundwater Basins. Proceedings of the Murray Darling Basin Groundwater Workshop 1999: 70-78. Murray Darling Basin Commission, Griffith.

Thurgate, M.E., Gough, J.S., Clarke, A.K., Serov, P. and Spate, A. (2001). Stygofauna diversity and distribution in Eastern Australian cave and karst areas. Records of the Western Australian Museum, Supplement No. 64: 49-62.

Thurgate, M.E., Spate, A. and Herr, A. (in press). Diversity at depth: the New South Wales cave invertebrate story. Helictite.

Wilson, G.D.F. and Johnson R.T. (1999). Ancient endemism among freshwater isopods (Crustacea, Phreatoicidea). In W. Ponder and D. Lunney (eds), The Other 99\%. The Conservation and Biodiversity of Invertebrates: 264-268. Royal Zoological Society of New South Wales, Mosman.

Manuscript received 17 May 2000, accepted 17 March 2001. 


\section{Appendix: Obligate Subterranean Invertebrate Fauna of New South Wales.}

The following list identifies those taxa that are obligate subterranean species. These have been subdivided according to the classifications used by Eberhard and Spate (1995) as indicated by the following codes: $\mathrm{Sb}=$ stygobite; $\mathrm{Tb}=$ troglobite; $\mathrm{Tp} 2=$ second-level troglophile. Where codes show (?) this classification is probable but as yet unconfirmed. The karst areas are shown by letter code at the end of each entry. Area codes are as follows: $\mathrm{A}=$ Abercrombie; $\mathrm{AS}=$ Ashford; $\mathrm{B}=$ Bungonia; $\mathrm{BN}=$ Borenore; $\mathrm{BP}=$ Bowan Park; $\mathrm{BS}=$ Bakers Swamp; $\mathrm{CB}=$
Comboyne; $\mathrm{CG}=$ Colong; $\mathrm{CL}=$ Cliefden; $\mathrm{CN}=$ Canomodine; $\mathrm{CP}=$ Cooleman Plain; $\mathrm{DE}=$ Deua; $\mathrm{I5L}=$ Talmo; J = Jenolan; JA = Jaunter; $\mathrm{KB}=$ Kunderang Brook; LW = Little Wombeyan Creek; MA = Marble Arch; $\mathrm{S}=$ Sulcor; $\mathrm{SC}=$ Stockyard Creek; $\mathrm{T}=$ Tuglow; $\mathrm{TR}=$ Timor; $\mathrm{W}=$ Wombeyan; $\mathrm{WA}=\mathrm{Walli}$; $\mathrm{WE}=$ Wellington; $\mathrm{WJ}=$ Wee Jasper; $W W=$ Willi Willi; $W Y=$ Wyanbene; $Y=$ Yarrangobilly; YE = Yessabah. Based on the New South Wales Cave Invertebrate database (Eberhard and Spate, 1995) and unpublished records.
Family, genus and species undetermined

Family, genus and species undetermined

F. Hydrobiidae
F. Ctenidae
F. Gradungulidae
F. Linyphiidae

F. Micropholocommatidae
F. Stiphidiidae
F. Synotaxidae
F. Textricellidae
F. Theridiidae

\section{F. Atemnidae \\ F. Cheliferidae \\ F. Chthoniidae}

Triaenonychidae
F. Urodinchychidae
F. Laelapidae
F. Rosensteiniidae

\section{Phylum Platyhelminthes \\ Class Turbellaria \\ Order Tricladida}

\section{Phylum Nemertina}

\section{Phylum Mollusca}

Class Gastropoda

Austropyrgus sp. nov. Austropyrgus sp. 1

$\begin{array}{ll}\mathrm{Sb} & \mathrm{A} ; \mathrm{B} ; \mathrm{LW} ; \mathrm{W} \\ \mathrm{Sb} ? & \mathrm{~W}\end{array}$

\section{$\mathrm{Sb} ? \quad \mathrm{CP} ; \mathrm{J} ; \mathrm{W}$}

$\mathrm{Sb}$ W W

\section{Phylum Chelicerata \\ Class Arachnida \\ Order Araneae}

gen. nov. (near Janusia) sp. nov.

gen. nov. sp. nov.

Laetesia weburdi (Urquhart, 1889)

gen. nov. (near Laetesia) sp. nov.

Chasmocephalon sp. 1

Procambridgea cavernicola Forster, 1973

gen. nov. sp. nov.

Textricella sp. nov.

Icona sp. nov. 1

Icona sp. nov. 2

Icona sp. nov. 3

Order Pseudoscorpiones

Oratemnus cavernicola Beier, 1976

Protochelifer cavernarum Beier, 1968

Protochelifer sp. near cavernarum

Pseudotyrannochthonius jonesi Chamberlin, 1962

Pseudotyrannochthonius sp.

Sathrochthonius tuena Chamberlin, 1962

Sathrochthonius sp. near tuena

Tyranochthonius cavicola Beier, 1962

Tyranochthonius sp. near cavicola

Order Opiliones

Holonuncia cavernicola Forster, 1955

H. dewae Hunt, 1992

H. sussa Hunt, 1992

H. weejasperensis Hunt, 1992

Holonuncia sp. nov.

\section{Order Acarina}

Uroobovella coprophila Womersley, 1960

Cosmolaelaps sp.

Hypoaspis sp.

Nycteriglypus dewae Womersley, 1963
Tp2 SC

$\mathrm{Tb} \quad \mathrm{J} ; \mathrm{W} ; \mathrm{Y}$

Tp2 J

$\mathrm{Tb} \quad \mathrm{Y}$

$\mathrm{Tb} \quad \mathrm{CN}$

Tp2 W; WJ;WY

$\mathrm{Tb} \quad \mathrm{MA} ; \mathrm{WY}$

$\mathrm{Tb} ? \quad \mathrm{CP}$

Tp2 B; CG; MA; T; W; J; SC

$\mathrm{Tb} \quad \mathrm{CL}$

$\mathrm{Tb} \quad \mathrm{Y}$

Tb? Tibooburra

Tp2 AS; CL; TR

Tp2 A; BN; S; SC; TR; W; WA; WJ; YE $\mathrm{Tb}$ unknown cave, Blue Mountains

$\mathrm{Tb} \quad \mathrm{SC}$

Tb DE; J; T;W; WJ

$\mathrm{Tb} \mathrm{T}$

$\mathrm{Tb} \quad \mathrm{B}$

$\mathrm{Tb} \quad \mathrm{I} 5 \mathrm{~L}$

$\begin{array}{ll}\text { Tp2 } & \text { J; TR; T } \\ \mathrm{Tb} & \mathrm{W} \\ \mathrm{Tb} & \mathrm{CG} \\ \mathrm{Tb} & \mathrm{WJ} \\ \mathrm{Tb} & \mathrm{TR}, \mathrm{CL}, \mathrm{A}, \mathrm{WY}\end{array}$

Tp2 CB; SC; W; WJ

Tp2 WJ

Tp2 CB

Tp2 W 


\section{Phylum Crustacea \\ Class Ostracoda}

Family, genus and species undetermined

Family, genus and species undetermined (sp. 1)

Family, genus and species undetermined (sp. 2)

\section{Class Copepoda}

Class Malacostraca

Division Syncarida

Order Anaspidacea

Family nov.

F. Psammaspididae

F. Neoniphargidae

F. Janiridae

F. Styloniscidae

Family Phreatoicidae

Crenoicus sp. nov.

Jasptorus solepti Bradbury and Williams, 1997

Neocrypta georginae Bradbury and Williams, 1997

N. moniae Bradbury and Williams, 1997

$N$. primaris Bradbury and Williams, 1997

N. robinae Bradbury and Williams, 1997

N. simoni Bradbury and Williams, 1997

Neoniphargus richardi Bradbury and Williams, 1997

N. secus Bradbury and Williams, 1997

Wombeyanus botulosus Bradbury and Williams, 1997

Gen. nov. 1 sp. nov. 1

Gen. nov. 1 sp. nov. 2

Gen. nov. 1 sp. nov. 3

Gen. nov. 1 sp. nov. 4

Gen. nov. 2 sp. nov.

Gen. nov. 3 sp. nov.

Gen. nov. 4 sp. nov.

Genus and species undetermined

Order Isopoda

Suborder Asellota

?Heterias sp.

Suborder Oniscidea

Genus and species undetermined

Suborder Phreatoicidea

\section{Phylum Uniramia}

Class Symphyla

Order Symphyla

Family, genus and species undetermined

\section{Class Insecta}

Order Collembola

F. Entomobryidae

F. Oncopoduridae

F. Sminthuridae

F. Neanuridae
Coecobrya sp. near hoefti

Sinella coeca group

Oncopodura sp.

Adelphoderia sp.

Kenyura sp.
$\mathrm{Sb} ? \quad \mathrm{~J} ; \mathrm{WJ}$

$\mathrm{Sb} ? \quad \mathrm{CP} ; \mathrm{J} ; \mathrm{W} ; \mathrm{WJ}$

$\mathrm{Sb} ? \quad \mathrm{~J}$

$\begin{array}{ll}\mathrm{Sb} & \mathrm{TR} \\ \mathrm{Sb} & \mathrm{WW} \\ \mathrm{Sb} & \mathrm{BS} \\ \mathrm{Sb} & \mathrm{BP} \\ \mathrm{Sb} & \mathrm{CL} \\ \mathrm{Sb} & \mathrm{CP} \\ \mathrm{Sb} & \mathrm{J} \\ \mathrm{Sb} & \mathrm{I} L \\ \mathrm{Sb} & \mathrm{WJ} \\ \mathrm{Sb} & \mathrm{WE} \\ \mathrm{Sb} & \mathrm{W} \\ \mathrm{Sb} & \mathrm{WY}\end{array}$

$\mathrm{Sb} \quad \mathrm{WJ}$

$\mathrm{Sb} \quad \mathrm{A}$

$\mathrm{Sb} \quad \mathrm{BP}$

$\mathrm{Sb} \quad \mathrm{WE}$

$\mathrm{Sb} \quad \mathrm{CN}$

$\mathrm{Sb} \quad \mathrm{J}$

$\mathrm{Sb} \quad \mathrm{W}$

$\mathrm{Sb} \quad \mathrm{W}$

$\mathrm{Sb} \quad \mathrm{W}$

$\mathrm{Sb} \quad \mathrm{W}$

$\mathrm{Sb} \quad \mathrm{W}$

$\mathrm{Sb} \quad \mathrm{CG}$

$\mathrm{Sb} \quad \mathrm{TR}$

$\mathrm{Sb} \quad W$

$\mathrm{Sb} \quad \mathrm{W}$

$\mathrm{Sb} \quad \mathrm{W}$

$\mathrm{Sb}$ ? J; W

Sb CP; WE

$\mathrm{Tb}$ ? B; CP; J; JA; T; W

$\mathrm{Sb} \quad \mathrm{J} ; \mathrm{WJ}$

$\mathrm{Tb}$ ? $\mathrm{B} ; \mathrm{CP} ; \mathrm{Y} ; \mathrm{W}$ 
F. Nicoletiidae

F. Carabidae

F. Cypselosomatidae
Order Thysanura

Trinemura anemone Smith, 1988

Order Coleoptera

Notospeophonus jasperensis ssp.

$N$. jasperensis jasperensis Moore, 1964

N. jasperensis vicinus Moore, 1964

Speotarus lucifugus lucifugus Moore, 1964

S. lucifugus princeps Moore, 1964

Teraphis cavicola Moore, 1977

Order Diptera

Cypselosoma australis McAlpine, 1966
$\mathrm{Tb} \quad \mathrm{B}$

Tp2 A

Tp2 WJ

Tp2 B

Tp2 AS

Tp2 WW

Tp2 Y

Tp2 SC 